\title{
Development of natural gum based glipizide mucoadhesive microsphere
}

\author{
Md. Abdur Rouf Al Mamun ${ }^{1}$, Monisha Bagchi ${ }^{1}$, Md. Lutful Amin ${ }^{1}$, Kumar Bishwajit Sutradhar ${ }^{1}$, Naz Hasan Huda ${ }^{2 *}$ \\ ${ }^{1}$ Department of Pharmacy, Stamford University Bangladesh, 51, Siddeswari Road, Dhaka- 1217, Bangladesh. \\ ${ }^{2}$ School of Pharmacy, Faculty of Health Sciences, CHIRI Biosciences Research Precinct, Curtin University, Perth, Western Australia, Australia.
}

\author{
ARTICLE INFO \\ Article history: \\ Received on: 20/10/2013 \\ Revised on: 26/11/2013 \\ Accepted on: 01/01/2014 \\ Available online: $30 / 01 / 2014$ \\ Key words: Glipizide, \\ mucoadhesive microsphere, \\ guar gum, xanthan gum, ionic \\ gelation method.
}

\begin{abstract}
The objective of this study was to develop glipizide microsphere with natural gums. Guar gum and xanthan gum were used separately in different ratios as natural polymers. The microspheres were prepared by orifice ionic gelation method and they were characterized by scanning electron microscopy and particle size analysis. Among six formulations, microspheres of four formulations (F1-F4) were discrete, sphrerical and free flowing. There was an inverse relationship found between the amount of gum and surface smoothness in case of guar gum-containing microspheres while a forward relationship was found between amount of gum and surface smoothness in case of the microspheres containing xanthan gum. The size of the particles increased with increasing amounts of gum. It can be concluded that guar gum and natural gum at a ratio of 1:0.25 and 1:0.5 can be ideal for formulating natural gum based glipizide mucoadhesive microsphere.
\end{abstract}

\section{INTRODUCTION}

Recently, dosage forms that can target a specific body site have been the area of interest in formulation and development of the novel drug delivery systems (Parmar et al., 2010). Microsphere is the carrier linked drug delivery system having particle size that ranges from $1-1000 \mu \mathrm{m}$ where a core of drug is dispersed in polymeric matrix and the core is surrounded by an outer layer of polymers (Prajapati et al., 2008). The use of microspheres spread from simple oral dosage form to as far as cancer drug delivery (Rajput and Agrawal, 2010). Microspeheres can be engineered in many ways to target the body sites accurately. In case of oral drug delivery, the success of these microspheres is limited due to their short residence time at the site of absorption (Patel et al., 2005; Amin et al., 2013). Therefore, it would be desirable to have them make an intimate contact with the absorbing membranes resulting in numerous advantages. This can be approached by combining mucoadhesion property to the microspheres. Mucoadhesion has been a topic of interest in

\footnotetext{
* Corresponding Author

Naz Hasan Huda, PhD Candidate, School of Pharmacy Faculty of Health Sciences, CHIRI Biosciences Research Precinct Curtin University, Kent Street, Post code: 6102 Perth, Western Australia, Australia.Cell: +61 42042 9681.E-mail: nazhasan@gmail.com
}

designing drug delivery systems to prolong the residence time of a dosage form at the site of absorption (Mathiowitz et al., 1997; Harsha et al., 2013). This mechanism of drug delivery offers efficient absorption and enhanced bioavailability of the drugs due to a high surface to volume ratio, a much more intimate contact with the mucus layer and specific targeting of drugs. Other advantages include rapid absorption due to enormous blood supply and good blood flow rates and protection of drug from degradation in the acidic environment of the gut (Patel et al., 2005; Asane et al., 2007). Type 2 diabetes mellitus (non-insulin dependent diabetes mellitus) is characterized by high blood glucose in the context of insulin resistance and relative insulin deficiency (Chiasson et al., 2002). Despite the availability of new agents for treatment, oral sulfonylureas remain a cornerstone of therapy which is associated with triggering insulin release by inhibiting the $\mathrm{K}_{\mathrm{ATP}}$ channel of the pancreatic beta cells (Gaba et al., 2011). Sulfonylureas are appealing in the treatment because they are relatively inexpensive and are well tolerated. Glipizide is a second-generation sulfonylurea that can lower the blood glucose level in humans by stimulating the release of insulin from the pancreas and typically prescribed to treat type II diabetes. Its biological half-life is short $(2-5 \mathrm{~h})$ and it possesses low gastric residence time (Verma and Garg, 2004; 
Patel et al., 2005; Jamzad and Fassihi, 2006). Absorption of oral glipizide is potentially affected by food intake, delaying the absorption (Ismail, 2009). Keeping in close contact with the mucosal layer (the unstirred layer) can facilitate its faster absorption. Natural gums are cheap, biodegradable, have good sticky property and do not require any organic solvents (Jani et al., 2009). Microspheres of glipizide have been prepared with synthetic polymers in recent researches (Behera et al., 2008; Phutane et al., 2010).

In this study, we attempted to develop formulations of glipizide microspheres with natural gums by orifice ionic gelation method which is simple and cost effective. We used two different natural gums separately in different amounts to formulate mucoadhesive microsphere of glipizide. Guar gum and xanthan gum were used as mucoadhesive polymers. Guar gum is extracted from the seed of the leguminous shrub Cyamopsis tetragonoloba. It is a reverse polysaccharide consisting of monosaccharide mannose and galactose units. Guar gum is hydrophilic and soluble both in cold and hot water (Soppirnath et al., 2002; Gaba et al., 2011). Xanthan gum is a polysaccharide secreted by the bacterium Xanthomonas campestris.

It is soluble in water and its solutions are neutral (GarciaOchoa et al., 2000). Both the gums have good mucoadhesive and biodegradable properties and require low concentration to become sticky very quickly, making them ideal for mucoadhesive carriers (Jani et al., 2009).

\section{MATERIALS AND METHODS}

\section{Materials}

Glipizide and Sodium alginate were purchased from Technodrugs \& Intermediates (P) Ltd., India and Merck KGaA, Germany, respectively. Guar gum and xanthan gum were purchased from Koster Keunen Inc., U.S.A. Calcium chloride was procured from Wilfrid Smith Ltd., UK.

\section{Preparation of mucoadhesive microsphere}

Glipizide Microspheres were prepared according to the method used by Mankala et al. (2011) by using different ratios of drug, sodium alginate, guar gum and xanthan gum (Table 1). Sodium alginate was dissolved in deionized water to form a homogeneous solution ( $2 \% \mathrm{w} / \mathrm{v})$. Guar gum and xanthan gum were dissolved separately with deionized water to get viscous and sticky solutions.

The pure drug was dispersed in the solution of gum and then sodium alginate solution was added to it with vigorous stirring until formation of an even dispersion. The resulting dispersion was then extruded drop wise into the calcium chloride solution $(10 \% \mathrm{w} / \mathrm{v})$ through a $23 \mathrm{G}$ syringe. The formed beads were retained in the calcium chloride solution for 15 minutes to complete the formation of spherical rigid microspheres. They were collected by decantation, washed with petroleum ether and dried at $45^{\circ} \mathrm{C}$ for 12 hours.

\section{Particle size}

Particle size of the prepared microspheres was determined by standard sieving method. Microspheres were weighed and spread on the upper sieve of an automatic sieve shaker (AS 200, Germany). The amount passed and retained on each sieve was weighed. The average particle size of each formulation was calculated using the following formula,

Mean particle size
$=\frac{\sum(\text { mean particle size of the fraction } \times \text { weight fraction })}{\sum(\text { weight fraction })}$

\section{Shape and surface morphology}

Shape and surface morphology of the microspheres were observed under electron scanning microscopy (SEM). Small amount of microspheres was spread on the glass stub and the stub containing the sample was placed in the scanning electron microscope (JEOL JSM - 6490 LA, Japan). Then SEM photographs were taken at an acceleration voltage of $20 \mathrm{kV}$. The drug-loaded microspheres were evaluated for their sphericity and surface smoothness.

\section{RESULTS}

Microspheres were formulated successfully with good spherecity except formula F5 and F6, which contained the highest amount of gum. They were very irregular in shape and their sizes were over $1000 \mu \mathrm{m}$. The performed tests indicated that formulations, containing lower amount of gum, had smaller particle size than the formulations that contained higher amount of gum (Table 1).

The SEM images illustrated that guar gum-containing microspheres were slightly more spherical than xanthan gumcontaining microspheres. Sphericity decreased with increasing amount of gum (Figure 1). In case of guar gum, microspheres had smoother surface with lower amount of gum. On the other hand, xanthan gum-containing formulations showed better smoothness in increased amount of gum (Figure 2).

\section{DISCUSSIONS}

Increased amount of gum might have interfered with the crosslinking process between sodium alginate molecules by calcium ions. Crosslinking of alginate molecules by divalent calcium ions of calcium chloride solution results in the formation of a closer network (calcium alginate coat) surrounding the beads. As we increased the amount of gum, extent of crosslinking decreased because the amount of sodium alginate remained same and additional amount of gum interfered with the crosslinking process between alginates molecules by calcium ions, being present on the surface. It might cause the irregular shape of the formulations that contained an increased amount of gum. As additional amount of gum increased the viscosity of the solution, so the drops became larger resulting in increased particle size. 
Table. 1: Composition and characteristics of the natural gum based glipizide mucoadhesive microspheres.

\begin{tabular}{|c|c|c|c|c|c|c|c|c|}
\hline Formulations & $\begin{array}{l}\text { Glipizide } \\
\text { (mg) }\end{array}$ & $\begin{array}{l}\text { Sodium alginate } \\
(\mathrm{mg})\end{array}$ & $\begin{array}{l}\text { Guar gum } \\
\quad(\mathbf{m g})\end{array}$ & $\begin{array}{c}\text { Xanthan gum } \\
(\mathrm{mg})\end{array}$ & $\begin{array}{c}\text { Crosslinking } \\
\text { agent }\left(\mathrm{CaCl}_{2}\right) \\
\text { w/v } \\
\end{array}$ & $\begin{array}{c}\text { Coat composition } \\
\text { (alginate-gum } \\
\text { ratio) }\end{array}$ & Sphericity & $\begin{array}{c}\text { Particle } \\
\text { size }(\mu \mathrm{m})\end{array}$ \\
\hline F1 & 50 & 50 & 12.5 & - & $10 \%$ & $1: 0.25$ & Spherical & 675.21 \\
\hline $\mathrm{F} 2$ & 50 & 50 & - & 12.5 & $10 \%$ & $1: 0.25$ & Spherical & 828.87 \\
\hline F3 & 50 & 50 & 25 & - & $10 \%$ & $1: 0.5$ & Spherical & 753.23 \\
\hline $\mathrm{F} 4$ & 50 & 50 & - & 25 & $10 \%$ & $1: 0.5$ & Spherical & 894.72 \\
\hline F5 & 50 & 50 & 37.5 & - & $10 \%$ & $1: 0.75$ & Very irregular & 1002.08 \\
\hline F6 & 50 & 50 & - & 37.5 & $10 \%$ & $1: 0.75$ & Very irregular & 1042.11 \\
\hline
\end{tabular}
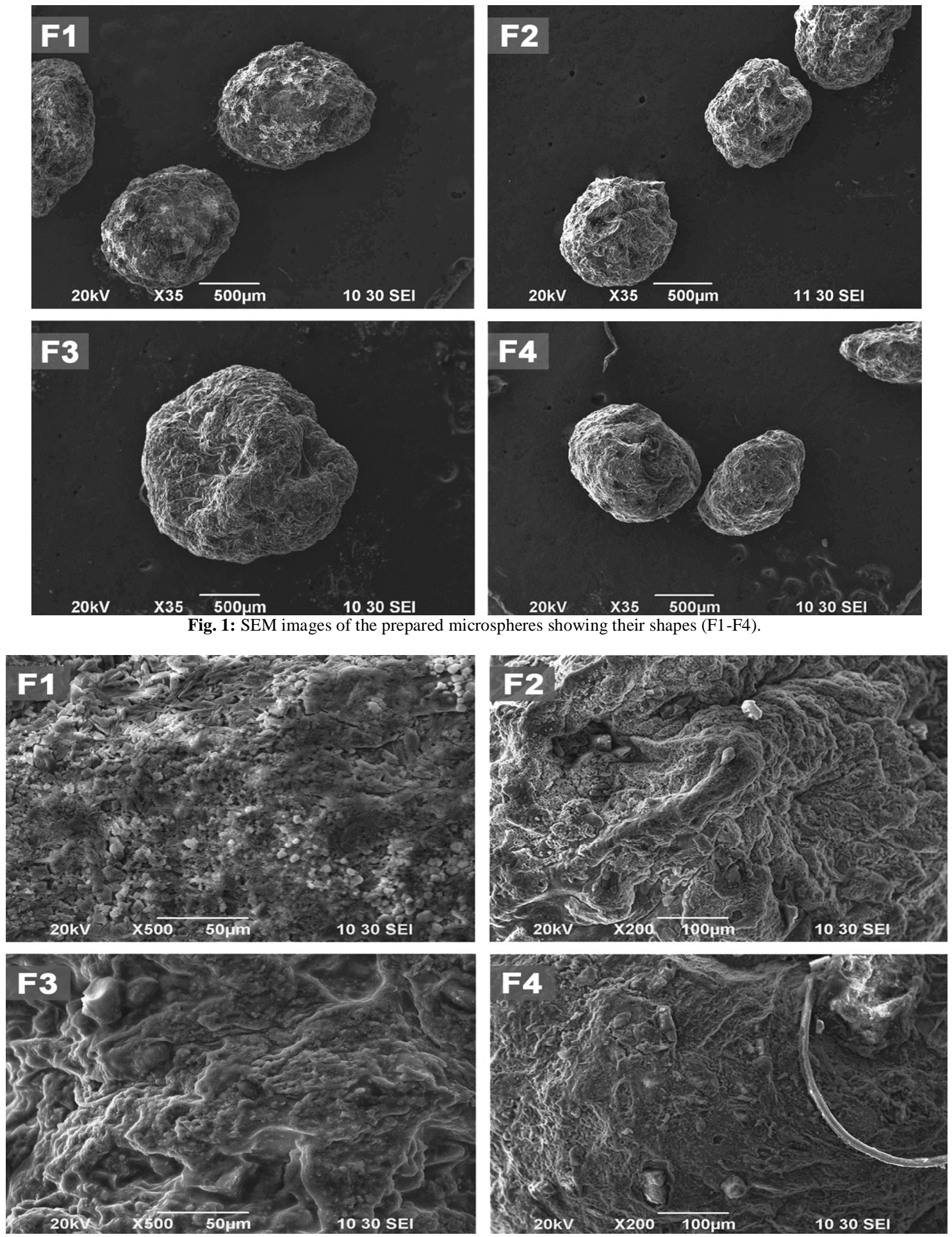

Fig. 2: Surface morphology of the microspheres from different batches (F1-F4). 


\section{CONCLUSION}

Mucoadhesive microspheres of glipizide with natural gums were successfully prepared by orifice ionic gelation method. Among six formulations, four formulations were found to be spherical and free flowing. The ratio of sodium alginate and gum at 1:0.25 and 1:0.5, were found to be optimum for the formulation of mucoadhesive microsphere. F1 and F4 possessed the best results among all the formulations in terms of surface smoothness and shape. Therefore, guar gum and xanthan gum can be considered as promising materials for designing glipizide mucoadhesive microspheres and further studies can be carried out.

\section{REFERENCES}

Amin ML, Jesmeen T, Sutradhar KB, Mannan MA. Development and in vitro evaluation of diclofenac sodium loaded mucoadhesive microsphere with natural gum for sustained delivery. Curr Drug Deliv, 2013; 10(6): 765-770.

Asane GS, Rao YM, Bhosale AV, Nirmal SA. Mucoadhesive gastro intestinal drug delivery system: an overview. Indian Drugs, 2007; 44:577-584.

Behera BC, Sahoo SK, Dhal S, Barik BB, Gupta BK. Characterization of glipizide-loaded polymethacrylate microspheres prepared by an emulsion solvent evaporation method. Trop J Pharm Res, 2008; 7:879-885.

Chiasson JL, Josse RG, Gomis R, Hanefeld M, Karasik A, Laakso M. Acarbose for prevention of type 2 diabetes mellitus: the STOPNIDDM randomised trial. Lancet, 2002; 359: 2072-2077.

Gaba P, Singh S, Gaba M, Gupta GD. Galactomannan gum coated mucoadhesive microspheres of glipizide for treatment of type 2 diabetes mellitus: in vitro and in vivo evaluation. Saudi Pharm J, 2011; 19:143-152.

Garcia-Ochoa F, Santos VE, Casas JA, Gomez E. Xanthan gum: production, recovery, and properties. Biotechnol Adv, 2000; 18:549-579.

Harsha S, Attimard M, Khan TA, Nair AB, Aldhubiab BE, Sangi S, Shariff A. Design and formulation of mucoadhesive microspheres of sitagliptin. J Microencapsul, 2013; 30:257-264.

Ismail MYM. Drug-food interactions and role of pharmacist. Asian J Pharm Clin Res, 2009; 2(4).
Jamzad S, Fassihi R. Development of a controlled release low dose class II drug-Glipizide. Int J Pharm, 2006; 312:24-32.

Jani GK, Shah DP, Prajapati VD, Jain VC. Gums and mucilages: versatile excipients for pharmaceutical formulations. Asian J Pharm Sci, 2009; 4:308-322.

Mankala SK, Nagamalli NK, Raprla R, Kommula R. Preparation and characterization of mucoadhesive microcapsules of gliclazide with natural gums. Stamford J Pharm Sci, 2011; 4(1):38-48.

Mathiowitz E, Jacob JS, Jong YS, Carino GP, Chickering DE, Chaturvedi P, Santos CA, Vijayaraghavan K, Montgomery S, Bassett $\mathrm{M}$, Morrell C. Biologically erodable microspheres as potential oral drug delivery systems. Nature, 1997; 386:410-414.

Parmar H, Bakliwal S, Gujarathi N, Rane B, Pawar S. Different methods of formulation and evaluation of mucoadhesive microsphere. Int $\mathrm{J}$ Appl Biol Pharm Tech, 2010; 1:1157-1167.

Patel JK, Patel RP, Amin AF, Patel MM. Formulation and evaluation of mucoadhesive glipizide microspheres. AAPS PharmSciTech, 2005; 6:E49-E55.

Phutane P, Shidhaye S, Lotlikar V, Ghule A, Sutar S, Kadam V. In vitro evaluation of novel sustained release microspheres of glipizide prepared by the emulsion solvent diffusion-evaporation method. J Young Pharm, 2010; 2:35-41.

Prajapati SK, Tripathi P, Ubaidulla U, Anand V. Design and development of gliclazide mucoadhesive microcapsules: in vitro and in vivo evaluation. AAPS PharmSciTech, 2008; 9:224-230.

Rajput MS, Agrawal P. Microspheres in cancer therapy. Indian J Cancer, 2010; 47:458-468.

Soppirnath KS, Aminabhavi TM. Water transport and drug release study from cross-linked polyacrylamide grafted guar gum hydrogel microspheres for the controlled release application. Eur $\mathrm{J}$ Pharm Biopharm, 2002; 53:87-98.

Verma RK, Garg S. Development and evaluation of osmotically controlled oral drug delivery system of glipizide. Eur J Pharm Biopharm, 2004; 57:513-525.

\section{How to cite this article:}

Md. Abdur Rouf Al Mamun, Monisha Bagchi, Md. Lutful Amin, Kumar Bishwajit Sutradhar, Naz Hasan Huda. Development of natural gum based glipizide mucoadhesive microsphere. J App Pharm Sci, 2014; 4 (01): 066-069. 